\title{
Penerapan Beton Kekuatan Awal Tinggi Untuk Percepatan Pekerjaan Jembatan Cast in Place Balanced Cantilever Prestressed Box Girder
}

\author{
Darmawan Adi Susanto ${ }^{1}$, Aleksander Purba ${ }^{2}$, Fauzan Murdapa ${ }^{3}$ \\ Program Profesi Insinyur, Universitas Lampung \\ Jl. Prof Sumantri Brojonegoro No.1 Bandar Lampung 35145 \\ ${ }^{1}$ dharmasinyo@gmail.com \\ ${ }^{2}$ aleksander.purba@eng.unila.ac.id \\ fauzan.murdapa@eng.unila.ac.id
}

Intisari - Percepatan konstruksi jembatan telah menjadi alternatif populer yang digunakan dalam pembangunan jembatan baru. Di Indonesia saat ini, masih banyak konstruksi jembatan Cast in Place Balanced Cantilever Prestressed Box Girder. Sebagai studi kasus, kajian ini dilakukan pada Proyek Pembangunan Jalan Tol Semarang - Solo Seksi 1, dalam lingkupnya proyek ini harus menyelesaikan 3 buah jembatan box girder yaitu Jembatan Banyumanik 1 (170m'), Jembatan Banyumanik 2 (384 m') dan Jembatan Gedawang (470m'). Percepatan masa konstruksi dilakukan dengan mempersingkat cycle time metode balanced cantilever dari 7 hari menjadi 5 hari, dengan mengurangi durasi curing time beton dari 3 hari menjadi 2 hari. Pada umur 2 hari kuat tekan beton harus mencapai 80\%* f'c (33.20 MPa) untuk keperluan prestressing tendons. Penelitian ini bertujuan untuk mengembangkan campuran beton kekuatan awal tinggi, membandingkan campuran beton dengan penambahan beberapa produk superplastisizer ditinjau dari aspek nilai slump dan kuat tekan, serta mendapatkan campuran beton dengan kuat tekan 80\%*f'c (33.20 MPa) pada umur 2 hari. Penelitian ini menggunakan metode eksperimen (trial mix) dengan menambahkan superplastisizer sikament LN dosis 1.7\%, Glenium C-315 dosis $1.2 \%$ dan ViscoCrete 3110 ID dosis $1.2 \%$ selanjutnya dilakukan uji kuat tekan pada umur 1,2,7 dan 28 hari. Benda uji berupa silinder beton $\emptyset 15 \times 30 \mathrm{~cm}$ dengan jumlah sampel 72 buah dan kuat tekan rencana 41.5 MPa. Hasil penelitian ini menunjukkan nilai slump ketiga campuran diatas $20 \pm 2 \mathrm{~cm}$, kuat tekan rerata tertinggi pada umur 1,2 dan 7 hari pada campuran beton dengan Glenium C-315 1.2\% (26.85 MPa, 37.52 MPa dan 44.78 MPa) dan umur 28 hari pada campuran beton dengan Sikament LN 1.7\% sebesar 51.33 MPa, kuat tekan karakteristik tertinggi umur 28 hari pada campuran beton dengan Sikament LN 1.7\% sebesar 49.55 MPa dan kuat tekan beton umur 2 hari yang sudah mencapai 80\% f'c (33.20 MPa) didapat pada campuran beton dengan Glenium C-316 1.2\% sebesar 37.52 MPa dan ViscoCrete 3110 ID 1.2\% sebesar 36.40 MPa.

Kata kunci - jembatan box girder, beton kekuatan awal tinggi, superplastisizer, kuat tekan.

Abstract - Accelerated bridge construction has become a popular alternative used in the construction of new bridges. In Indonesia today, there is still a lot of Cast in Place Balanced Cantilever Prestressed Box Girder bridge construction. As a case study, this study was carried out on the Semarang - Solo Toll Road Development Project Section 1, within the scope of this project, it must complete 3 box girder bridges, namely the banyumanik1 bridge-170m ', banyumanik2 bridge-384 $\mathrm{m}^{\prime}$ and the gedawang bridge-470m'. The acceleration of the construction period is done by shortening the cycle time of the balanced cantilever method from 7 days to 5 days, by reducing the duration of the concrete curing time from 3 days to 2 days. At the age of 2 days the concrete compressive strength must reach $80 \% * \mathrm{f}$ 'c $(33.20 \mathrm{MPa})$ for the purposes of prestressing tendons. This study aims to develop high early strength concrete mixture, compare concrete mixture with the addition of several superplasticizer products in terms of slump value and compressive strength, and obtain concrete mixes with $80 \% *$ f'c $(33.20 \mathrm{MPa})$ compressive strength at 2 days. This study used an experimental method (trial mix) by adding a superplastisizer; Sikament LN dose 1.7\%, Glenium C-315 dose $1.2 \%$ and ViscoCrete 3110 ID dose $1.2 \%$ and then the compressive strength test was performed at ages 1,2,7 and 28 days. The specimen was a concrete cylinder $\emptyset 15 \times 30 \mathrm{~cm}$ with a total sample of 72 pieces and a compressive strength of $41.5 \mathrm{MPa}$. The results of this study indicate the value of the third slump mixture above $20 \pm 2 \mathrm{~cm}$, the highest average compressive strength at ages 1.2 and 7 days in concrete mixtures with Glenium $\mathbf{C}-315$ 1.2\% (26.85 MPa, 37.52 MPa and 44.78 MPa) and 28 days in concrete mix with Sikament LN 1.7\% of 51.33 
MPa, the highest compressive strength characteristic of 28 days in concrete mixture with Sikament LN $1.7 \%$ of 49.55 MPa and compressive strength of 2-day age concrete that has reached $80 \%$ f'c obtained in concrete mixture with Glenium C-316 1.2\% at 37.52 MPa and ViscoCrete 3110 ID 1.2\% at 36.40 MPa.

Keywords - box girder bridge, high early strength concrete, superplastisizer, compressive strength.

\section{PENDAHULUAN}

Percepatan konstruksi jembatan telah menjadi alternatif populer yang digunakan dalam pembangunan jembatan baru. Di Indonesia saat ini masih banyak konstuksi jembatan cast in place balanced cantilever prestressed box girder, Metode balance cantilever, salah satunya pada Proyek Pembangunan Jalan Tol Semarang - Solo Paket 1 dimana memiliki lingkup pekerjaan 3 buah jembatan box girder dengan metode balanced cantilever yaitu jembatan banyumanik1 (170 m'), jembatan banyumanik2 (384 m') dan jembatan gedawang $(470 \mathrm{~m}$ ') dikarenakan masa konstruksi yang singkat maka dilakukan upaya memperpendek durasi cycle time metode balanced cantilever dari 7 hari menjadi 5 hari, salah satu aktifitas sequence pada metode ini adalah curing concrete yang berdurasi standar 3 hari, akan diperpendek menjadi 2 hari dengan target kuat tekan beton sudah mencapai $80 \%$ kuat tekan rencana. Saat ini sudah banyak inovasi teknologi beton guna menjawab tantangan akan kebutuhan diatas, beton yang dihasilkan diharapkan memiliki kualitas tinggi meliputi kekuatan dan daya tahan. Rekayasa mengenai penambahan concrete admixture (superplasticizer) dengan dosis tertentu yang dapat menambah kekuatan tekan pada beton agar mendapatkan nilai kuat tekan yang tinggi. Saat ini banyak produsen menawarkan produk concrete admixture guna mendapatkan campuran beton dengan kekuatan awal tinggi.

Berdasarkan uraian tersebut, tujuan penelitian ini adalah untuk mengembangkan campuran beton dengan kekuatan awal tinggi, membandingkan campuran beton dengan penambahan admixture antara beberapa produk superplastisizer ditinjau dari aspek nilai slump dan kuat tekan serta mendapatkan campuran beton dengan kuat tekan $80 \%$ f'c pada umur 2 hari.

\section{KAJIAN PUSTAKA}

\section{A. Jembatan Cast in Place Balance Cantilever Prestressed Box Girder}

Referensi [1] menjelaskan bahwa konstruksi segmental balanced cantilever pada jembatan box girder beton, telah lama direkomendasikan sebagai salah satu metoda yang efisien dalam pembangunan sebuah jembatan tanpa menggunakan perancah. Konstruksi dilakukan dari pilar permanen dan proses selanjutnya dengan cara "balanced" ke arah span tengah sampai dengan sambungan terakhir. Kantilever biasanya dibuat $3-6 \mathrm{~m}$ panjang tiap segmen. Segmen ini dapat dapat dikonstruksi dengan cara cor di tempat atau dengan beton precast. Teknik pengecoran ditempat lebih sesuai untuk span panjang dan tidak seragam.

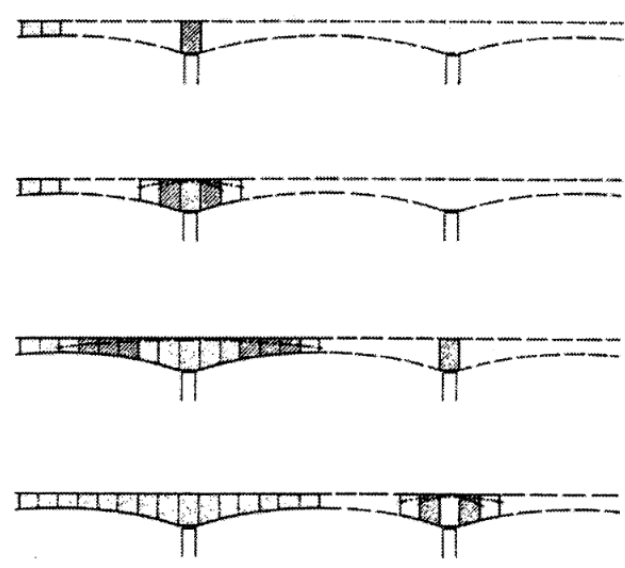

Gbr 1. Konstruksi balanced cantilever [1]

Dalam [2] dijelaskan mengenai overview langkah pengecoran dan cycle time pengecoran balanced cantilever cast in place prestressed box girder yang ditunjukkan pada tabel berikut ini:

Tabel 1. Tipikal Durasi Langkah Pengecoran

\begin{tabular}{|c|l|}
\hline $\begin{array}{c}\text { Durasi } \\
\text { (hari) }\end{array}$ & \multicolumn{1}{c|}{ Aktifitas } \\
\hline 1 & $\begin{array}{l}\text { Post-tensioning tendon pada } \\
\text { segmen sebelumnya } \\
\text { Pelepasan formwork }\end{array}$ \\
\hline
\end{tabular}




\begin{tabular}{|c|l|}
\hline & Penggeseran traveller form \\
\hline 2 & $\begin{array}{l}\text { Pemasangan besi tulangan, } \\
\text { ducting dan tendon }\end{array}$ \\
\hline 1 & $\begin{array}{l}\text { Pengecoran bottom slab, web dan } \\
\text { top slab }\end{array}$ \\
\hline 3 & $\begin{array}{l}\text { Curing concrete (termasuk hari } \\
\text { minggu) }\end{array}$ \\
\hline 7 & Total durasi 7 hari \\
\hline
\end{tabular}

Dari tabel diatas diperoleh durasi total cycle time per segmen pengecoran adalah 7 hari, salah satu upaya untuk mempersingkat durasi tersebut dengan memempercepat curing time dari 3 hari menjadi 2 hari dengan membuat campuran beton kekuatan awal tinggi (High Early Strength Concrete) dengan menambahkan concrete admixture (superplastisizer) sebagai bahan tambahnya.

\section{B. Definisi Beton}

Beton merupakan suatu bahan campuran dari beberapa material, yang bahan utamanya terdiri dari campuran antara semen, agregat halus, agregat kasar, air serta bahan tambahan lain dengan perbandingan tertentu. Karena beton merupakan campuran, maka kualitas beton sangat tergantung dari kualitas masing- masing material pembentuknya [3].

\section{Beton Segar (Fresh Concrete)}

1) Kelecakan (Workability),

Dalam [4] workability didefinisikan sebagai suatu ukuran dari beton segar atau mortar yang menentukan tingkat kemudahan beton dalam pencampuran, pengecoran, pemadatan dan tetap dengan kondisi homogen.

\section{2) Pemisahan Air ke Permukaan (Bleeding)}

Dalam [4] dijelaskan definisi bleeding adalah pengeluaran air dari adukan, pada beton yang baru di cor atau mortar, yang disebabkan oleh penurunan material padat di dalam masa beton atau disebut pelepasan air.

\section{3) Pemisahan Butiran (Segregation),}

Dalam [4] dijelaskan definisi segregasi adalah pemisahan konsentrasi komponen penyusun campuran beton, agregat atau sejenisnya, mengakibatkan ketidakseragaman proporsi pada masa beton.

\section{4) Pengujian Slump (Slump Test)}

Referensi [7] menjelaskan, slump beton adalah salah satu ukuran kekentalan adukan beton dinyatakan dalam $\mathrm{mm}$ ditentukan dengan alat kerucut abram, Dalam [9] juga menjelaskan definisi slump adalah ukuran kekentalan dari campuran beton segar, mortar atau plesteran yang setara tinggi campuran diukur terdekat bagian $1 / 4$ in $(6 \mathrm{~mm})$ dari cetakan benda uji sesaat setelah pemindahan kerucut slump.

\section{Beton Keras (Hardened Concrete)}

\section{1) Kuat Tekan Beton}

Campuran beton dapat di desain untuk mendapatkan jangkauan sifat sifat mekanis dan durabilitas yang memenuhi persyaratan desain suatu struktur. Kuat tekan adalah sebuah atribut umum mutu yang digunakan para insinyur untuk memdesain suatu struktur. Kuat tekan diukur dengan cara memecahkan beton silinder dalam mesin uji kuat tekan. Kuat tekan dihitung dengan cara mebagi beban maksimum saat benda uji pecah dengan luas penampang benda uji dengan satuan psi atau MPa [10]. Dalam [11] dijelaskan mengenai tata cara pengujian kuat tekan beton dan perhitungan kuat tekan dari benda uji diperoleh dengan cara membagi beban maksimum yang diberikan pada benda uji dengan luas penampang benda uji tersebut.

\section{2) Faktor Air Semen (FAS)}

Faktor air semen (FAS) adalah angka perbandingan antara berat air bebas dan berat semen dalam beton [7]. Dalam [5] dijelaskan bahwa perbandingan FAS sangat menentukan mutu kekuatan beton. Nilai FAS yang semakin tinggi menyebabkan mutu kekuatan beton akan semakin rendah, namun nilai semakin rendah nilai FAS tidak bisa diartikan bahwa kekuatan beton semakin tinggi. Nilai FAS yang rendah menyebabkan kesulitan dalam pengerjaan, sehingga pemadatan beton akan sulit dilakukan dan mengakibatkan mutu beton menjadi turun. Umumnya nilai FAS minimum yang diberikan sekitar 0.4 dan maksimum 0.65. Hampir untuk semua tujuan, beton yang mempunyai faktor air semen minimal dan cukup untuk memberikan workabilitas tertentu yang dibutuhkan untuk pemadatan yang sempurna tanpa pekerjaan 
pemadatan yang berlebihan, merupakan beton yang terbaik [18].

\section{E. Concrete Admixture (Superplasticizer)}

Admixture adalah material selain air, agregate, material semen hidrolik, dan serat yang digunakan sebagai bahan campuran beton untuk mendapatkan campuran segar, setting time, dan pengerasan yang ditambahkan pada campuran beton sebelum atau sesudah pencampuran [12]. Dalam [13] disebutkan tipe-tipe chemical admixtures; Tipe A. Waterreducing admixtures, Tipe B. Retarding admixtures,Tipe C. Accelerating admixtures, Tipe D. Water-reducing and retarding admixtures, Tipe E. Water-reducing and accelerating admixtures, Tipe F. Water-reducing and high range admixtures, Tipe G. Water-reducing, high range and retarding admixtures.

\section{1) Sikament $L N$}

Referensi [14] menjelaskan Sikamen LN adalah bahan tambah yang sangat efektif untuk mengurangi kadar air dan merupakan superplastisizer yang dapat meningkatkan percepatan pengerasan dengan workability yang tinggi. Sesuai dengan ASTM C 494 Type F. Bahan tambah ini bisa mengurangikadar air hingga $20 \%$ dan akan menaikkan $40 \%$ kuat tekan pada umur 28 haridosis pada campuran beton berkisar $0.6 \%-1.5 \%$ terhadap berat semen.

\section{2) Glenium $C$-316}

Referensi [16] menjelaskan Glenium C-316 adalah generasi baru untuk mengurangi kadar air, berbahan dasar polycarboxic ether, dikhususkan untuk industri beton yang memerlukan slump retention, memiliki kekuatan dan daya tahan tinggi dan sesuai untuk cuaca panas. Glenium C-316 didesain sesuai dengan ASTM C 494 Type F. Dosis pada campuran beton berkisar 0.8 - 2.0 liter per 100 $\mathrm{kg}$ berat semen.

\section{3) Sika ViscoCrete - 3110 ID}

Referensi [15] menjelaskan Sika ViscoCrete 3110 ID adalah superplastisizer generasi ke-3 pada beton dan mortar. Bahan tambah ini khusus untuk pengembangan produksi beton encer dengan pengecualian penundaan flow properties. Bahan ini sesuai dengan ASTM C 494 Type G dan BS 5075: Part 3. Bahan tambah ini bisa mengurangi kadar air hingga $30 \%$ dan memiliki kekuatan tinggi. Dosis pada ca7]mpuran beton berkisar $0.6 \%-1.8 \%$ terhadap berat semen.

\section{F. High Early Strength Concrete}

Referensi [17] menjelaskan High Early Strength Concrete merupakan salah satu tipe beton mutu tinggi. Kekuatan awal beton yang tinggi adalah kuat tekan beton pada 24 jam pertama setelah pengecoran di lapangan dapat mencapai kuat tekan $35 \mathrm{MPa}$ dengan faktor air semen maksimum 0.35 dan frost durability mínimum $80 \%$.

\section{METODOLOGI PENELITIAN}

\section{A. Lokasi dan Sampel Penelitian}

Penelitian ini dilakukan laboratorium beton Proyek Pembangunan Jalan Tol Semarang - Solo Paket 1, Semarang, Jawa tengah. Sampel penilitian ialah benda uji yang berupa silinder dengan ukuran dia. $15 \mathrm{~cm}$ tinggi $30 \mathrm{~cm}$, terdiri dari benda uji beton beton normal dengan penambahan superplasticizer Sikament LN 1.7\% (S. LN), Glenium C-316 1.2\% (S. 316) dan ViscoCrete 3110 ID 1.2\% (S. 3110) yang akan diuji pada umur 1, 2, 7 dan 28 hari. Jumalah benda uji sebanyak 72 buah. Kuat tekan beton rencana pada umur 28 hari adalah $41.5 \mathrm{MPa}$.

\section{B. Material}

Agregat halus merapi Klaten Jawa Tengah, Agregat kasar (split/batu pecah $1 / 2$ dan 2/3) Gringsing Batang Jawa tengah, Air sumur artesis desa Kramas Semarang Jawa Tengah, Portland Cement tipe I produksi semen gresik dan superplastisizer (Sikament LN, Glenium C-315 dan ViscoCrete 3110 ID).

\section{Peralatan}

Centing semen, cawan alumunium, cawan plastik, timbangan digital, analisa saringan, mesin Los Angeles, kerucut Abrams, gelas ukur, tabung pitot, mistar ukur, molen, cetakan silinder $\emptyset 15$ x $30 \mathrm{~cm}$, kunci dan compressive strength machine. Standar pengujian mengacu pada Peraturan Beton Indonesia 1971 [6], SNI 03-2834-2002 Tata Cara Pembuatan Campuran Beton Normal [7], SNI 03- 
2847-2002 Tata Cara Perencanaan Struktur Beton Untuk Bangunan Gedung [8].

\section{Metode Penelitian}

Metode penelitian yang digunakan dalam perencanaan campuran beton normal dengan menggunakan bahan tambah kimia superplasticizer adalah metode trial mix atau biasa disebut metode eksperimen. Eksperimen yang dilakukan adalah dengan membuat campuran beton dengan menambahkan beberapa macam produk superplasticizer Sikament LN $1.7 \% \quad$ (S. LN), Glenium C-316 1.2\% (S. 316) dan ViscoCrete 3110 ID $1.2 \%$ (S. 3110), Dari hasil pengujian ketiga campuran tersebut akan dibandingkan aspek kelecakan, kuat tekan rata-rata pada umur 1,2,7 dan 28 hari dan kuat tekan karakteristik umur 28 hari. Dalam penelitian juga akan membandingkan hasil kuat tekan beton umur 2 hari dimana percepatan cycle time metode balanced cantilever dilakukan dengan cara mempersingkat durasi curing time beton menjadi 2 hari dengan syarat kuat tekan beton umur 2 hari sudah mencapai target $0.80 \mathrm{f}^{\prime} \mathrm{c}=33.20$ MPa.

\section{E. Alur Penelitian}

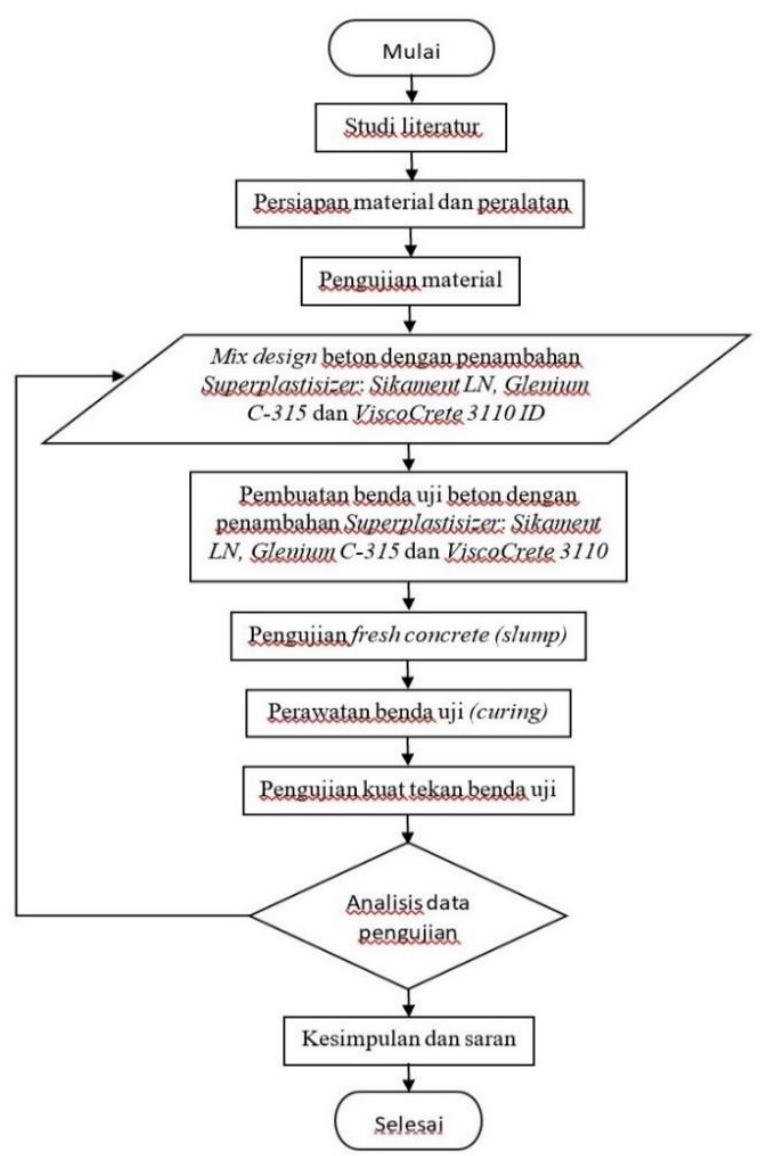

Gbr 2. Flowchart penelitian

\section{HASIL PENGUJIAN DAN PEMBAHASAN}

A. Mix Design dan Hasil Pengujian Nilai Slump

Tabel 2. Mix Design Beton

\begin{tabular}{|l|c|c|c|}
\hline \multicolumn{1}{|c|}{ Uraian } & S. LN & S. 315 & S. 3110 \\
\hline WC ratio & 0.32 & 0.31 & 0.29 \\
\hline Air & 184 & 153 & 146 \\
\hline PC tipe 1 & 560 & 500 & 500 \\
\hline Pasir & 620 & 674 & 776 \\
\hline Split 5-10 & - & 301 & 313 \\
\hline Split 10-20 & 1128 & 875 & 729 \\
\hline Sikament LN & $1.7 \%$ & $1.2 \%$ & $1.2 \%$ \\
\hline Slump rerata & 20 & 22 & 20 \\
\hline
\end{tabular}




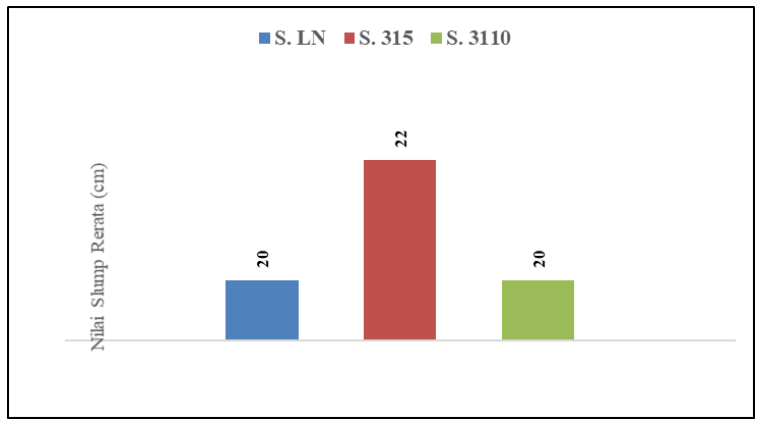

Gbr 3. Pengaruh Penggunaan Superplasticizer Terhadap Nilai Slump.

Gambar 3 menunjukkan hasil pengujian slump pada masing-masing sampel benda uji silinder beton, campuran beton dengan penambahan superplastisizer Sikament LN $1.7 \% \quad 20 \mathrm{~cm}$, Glenium C-316 $1.2 \% 22 \mathrm{~cm}$ dan ViscoCrete 3110 ID $1.2 \% 20 \mathrm{~cm} . d$ Dengan nilai slump $20 \pm 2 \mathrm{~cm}$, sehingga beton segar memiliki workability yang cukup baik dan bisa diterapkan pada pengecoran cast in place box girder metode balanced cantilever.

\section{B. Hasil Pengujian Kuat Tekan}

Tabel 3. Hasil Pengujian Kuat Tekan Rerata

\begin{tabular}{|c|c|c|c|c|}
\hline \multirow{2}{*}{$\begin{array}{c}\text { Kode } \\
\text { Benda } \\
\text { Uji }\end{array}$} & \multicolumn{4}{|c|}{ Kuat Tekan Rerata (MPa) } \\
\cline { 2 - 5 } & $\mathbf{1}$ hari & $\mathbf{2}$ hari & $\mathbf{7 ~ h a r i}$ & $\mathbf{2 8}$ hari \\
\hline S. LN & 20,38 & 29,47 & 40,02 & 51,33 \\
\hline S. 315 & 26,85 & 37,52 & 44,78 & 49,23 \\
\hline S. 3110 & 22,49 & 36,40 & 41,53 & 46,69 \\
\hline
\end{tabular}

Dari Tabel 3 dan Gambar 3 menunjukkan hasil pengujian kuat tekan rerata beton pada masingmasing benda uji. Umur 1 hari kuat tekan tertinggi pada campuran beton Glenium C-316 26.85 MPa, umur 2 hari kuat tekan tertinggi pada campuran beton Glenium C-316 37.52 MPa, umur 7 hari kuat tekan tertinggi Glenium C-316 $44.78 \mathrm{MPa}$ dan umur 28 hari kuat tekan tertinggi pada Sikament LN $51.33 \mathrm{MPa}$.

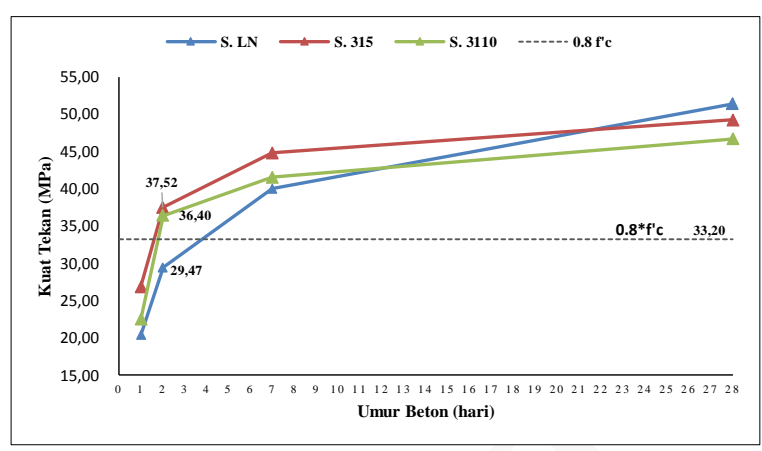

Gbr 4. Kekuatan Tekan Beton Berdasarkan Umur Pengujian

Untuk mempercepat cycle time metode balanced cantilever dilakukan dengan cara mempersingkat durasi curing time beton menjadi 2 hari dengan syarat kuat tekan beton umur 2 hari sudah mencapai $0.80 \mathrm{f}^{\prime} \mathrm{c}$ atau $33.20 \mathrm{MPa}$, sehingga pekerjaan prestressing tendon dapat dilakukan. Dari Gambar 4 menunjukkan, pada umur 2 hari diperoleh campuran beton yang mempunyai kuat tekan rerata $\geq 0.80 \mathrm{f}$ 'c atau $\geq 33.20 \mathrm{MPa}$ pada campuran beton dengan penambahan superplastisizer Glenium C$3161.2 \% 37.52 \mathrm{MPa}$ dan ViscoCrete 3110 ID 1.2\% $36.40 \mathrm{MPa}$.

Tabel 4. Hasil Pengujian Kuat Tekan Karakteristik umur 28 hari

\begin{tabular}{|c|c|}
\hline $\begin{array}{c}\text { Kode } \\
\text { Benda Uji }\end{array}$ & $\begin{array}{c}\text { Kuat Tekan Karakteristik } \\
\text { (MPa) }\end{array}$ \\
\hline S. LN & 49.55 \\
\hline S. 315 & 48.75 \\
\hline S. 3110 & 46.17 \\
\hline
\end{tabular}

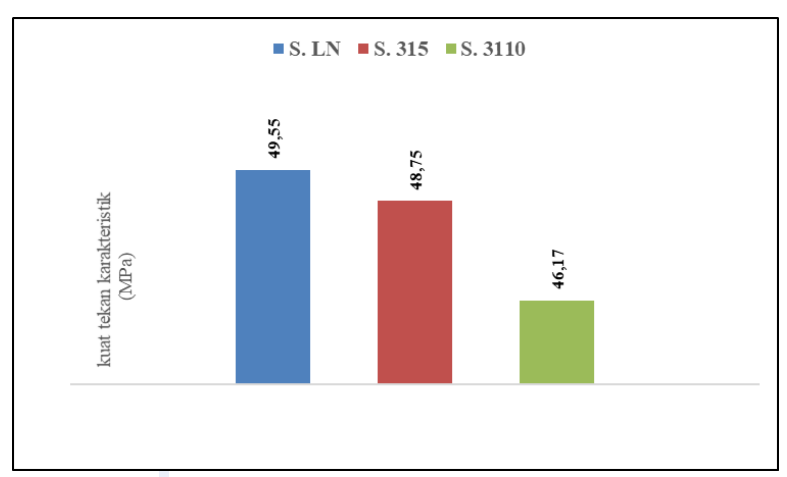

Gbr 5. Kuat tekan karakteristik beton umur 28 hari

Tabel 4 dan Gambar 5 menunjukkan kuat tekan karakteristik beton pada umur 28 hari, kuat tekan tertinggi diperoleh pada campuran beton dengan penambahan superplastisizer Sikament LN 1.7\% 
49.55 Mpa, kemudian Glenium C-316 1.2\% 48.75

$\mathrm{MPa}$ dan yang paling rendah ViscoCrete 3110 ID $1.2 \%$ 46.17 MPa.

\section{KESIMPULAN DAN SARAN}

\section{A. Kesimpulan}

1) Dari ketiga sampel campuran beton dengan penambahan superplastisizer diperoleh nilai slump $20 \pm 2 \mathrm{~cm}$, sehingga beton segar memiliki workability yang cukup baik dan bisa diterapkan pada pengecoran cast in place box girder metode balanced cantilever.

2) Kuat tekan rerata tertinggi pada umur beton 1,2 dan 7 hari diperoleh pada campuran beton dengan penambahan superplastisizer Glenium C-316 1.2\% (26.85 MPa, 37.52 MPa dan 44.78 $\mathrm{MPa}$ ), sedangkan padaumur 28 hari pada campuran beton superplastisizer Sikament LN $1.7 \%$ sebesar $51.33 \mathrm{MPa}$.

3) Kuat tekan karakteristik beton umur 28 hari diperoleh pada campuran beton dengan penambahan superplastisizer Sikament LN 1.7\% sebesar 49.55 MPa.

4) Kuat tekan campuran beton dengan penambahan superplastisizer Glenium C-316 $1.2 \%$ sebesar $37.52 \mathrm{MPa}$ dan ViscoCrete 3110 ID $1.2 \%$ sebesar $36.40 \mathrm{MPa}$ dapat diaplikasikan pada percepatan cycle time konstruksi jembatan balanced cantilever prestressed box girder karena pada umur beton 2 hari kuat tekan beton $\geq 0.80 \mathrm{f}^{\prime} \mathrm{c}$ atau $\geq 33.20 \mathrm{Mpa}$.

\section{B. Saran}

1) Perlu adanya penelitian lebih lanjut untuk penerapan beton kekuatan awal tinggi, dengan bahan tambah admixture yang update saat ini dengan tujuan pada saat umur beton $<2$ hari diperoleh kekuatan beton yang tinggi sesuai keperluan stressing tendon sehingga cycle time konstruksi bisa dipersingkat lagi.

2) Perlu adanya penelitian lebih lanjut mengenai pengaruh penggunaan admixture pada High Early Strength Concrete berdasarkan penelitian ini ditinjau dari aspek sifat-sifat beton yang lainnya antara lain rangkak, susut, reaksi terhadap suhu, keawetan dan kekedapan air.

\section{REFERENSI}

[1] Sauvageot, G. "Segmental Concrete Bridges.", Bridge Engineering Handbook, Ed. Wai-Fah Chen and Lian Duan, Boca Raton: CRC Press, 2000.

[2] G Lucko. (1999), Chapter 4: The Construction Process of Segmental Bridges. Diambil dari https://scholar.lib.vt.edu/theses/available/etd120199.../11lucko_chapter4.pdf.

[3] Tjokrodimulyo, Kardiyono. Teknologi Beton. Biro Penerbit. Yogyakarta, 1992.

[4] Tjokrodimulyo, Kardiyono. Teknologi Beton. Buku Bahan Ajar Jurusan Teknik Sipil Fakultas Teknik UGM. Yogyakarta, 1995.

[5] Tri Mulyono, Teknologi Beton, Andi Offset. Yogyakarta. 2003.

[6] Peraturan Beton Bertulang Indonesia 1971 Bandung, 1971.

[7] SNI 03-2834-2002, "Tata Cara Pembuatan Rencana Campuran Beton Normal", Badan Standarisasi Nasional, 2002.

[8] SNI 03-2847-2002 "Tata Cara Perencanaan Struktur Beton Untuk Bangunan Gedung", Badan Standarisasi Nasional, 2002.

[9] ACI 116R-00, Cement and Concrete Terminology.

[10] National Concrete Ready Mixed Association, NRMCA, "Concrete in Practice", 2003.

[11] ASTM C39/C39 M - 99, Standard Test Method for Compressive Strength and Cylindrical Concrete Specimens.

[12] ASTM C125 - 03, Standard Terminology Relating to Concrete and Concrete Aggregate.

[13] ASTM C494/C 494 M - 99a, Standard Specification for Chemical Admixtures for Concrete.

[14] Sika Technical Data Sheet, Edition 3, 2007.

[15] Sika Technical Data Sheet, Edition 3, 2008.

[16] BASF Technical Data Sheet, 2009.

[17] P. Zia, S. H.Ahmad, J.J. Schemmel and R. P. Ellion, "Mechanical Behavior of High Performance Concrete, Volume 4, High Early Strength Concrete," Strategic Highway and Research Program, National Academy of Sciences, Washington DC 1993.

[18] L.J. Murdock dan K.M. Brook. Bahan dan Praktek Beton, Erlangga, Jakarta, 1979. 